\title{
Begging for bags: \\ BAG-raising and prescriptive ideologies in Spokane Washington
}

\author{
Drew Crosby \& Amanda Dalola*
}

\begin{abstract}
Prevelar raising, the raising of $/ æ /$ and $/ \varepsilon /$ before $/ \mathrm{g} /$ and $/ \mathrm{y} /$, has been noted during the last decade as a feature of Pacific Northwest English (PNWE). Previous research has focused mainly on gender and age as predictors, revealing a complex interplay that generally points to a decline in usage among younger generations. The present research reveals contradictory findings and identifies a novel category in the debate - speaker attitude towards the variable - which is found to condition it more robustly than other established predictors.
\end{abstract}

Keywords. BAG-raising; Washington State English; Pacific Northwest English; linguistic ideologies; BAG-tensing; prescriptivism; prevelar raising

1. Introduction. In the Atlas of North American English (ANAE), Labov, Ash, and Boberg (2006) conducted a telephone survey, Telsur, of 762 speakers of North American English. They used the data obtained from these telephone interviews to analyze the phonological systems of the urbanized areas of speakers of North American English. In doing so, they divided up the urban varieties of North American English (NAE) into ten different "regions," many of which are internally divided into different "dialects." One of the regions that did not display enough internal differentiation to warrant smaller dialect divisions was the West, which Labov et al. (2006) characterize as "[lacking] the high levels of homogeneity and consistency ... found for most other dialects" (p. 284). However, despite this characterization, the West does indeed have both a degree of consistency and internal differentiation. In the case of the former, it is differentiated from surrounding regions by the cot-caught merger (in comparison to the North dialect region), lack of Canadian raising, and fronting of /u/ but not /o/ (Labov et al. 2006: 137). In the case of the latter, the multiple vowel systems regrouped under the heading of 'the West' show differentiation in their degree of fronting of the back rounded vowels and in the presence or absence of certain phonological processes. (Wassink 2015; Wassink 2016). Specifically, Wassink (2015) shows that in contrast to California, ${ }^{1}$ where both $/ \mathrm{u} /$ and $/ \mathrm{o} /$ have been shown to be fronted (Eckert 2005), speakers of English in the Seattle metropolitan area only display /u/ fronting. In addition to this, speakers in Washington state display two similar phonological phenomena quite different from speakers of other western dialects: BAG-raising, the raising of /æ/ to a higher position before the voiced velars stops, $/ \mathrm{g} /$ and $/ \mathrm{y} /$, and BEG-raising, the raising of $/ \varepsilon /$ in the same environment (Freeman 2014; Wassink 2015; Wassink 2016; Mielke, Carignan, and Thomas 2017).

2. BAG/BEG-raising. BAG-raising is a phenomenon that is not unique to the dialects of Washington State, although, it and BEG-rising do "play an important role in regional differentiation" from surrounding dialects (Wassink 2016: 98). It has also been attested in Wisconsin (Zeller 1997), as well as Minnesota and central Canada (Labov et al. 2006). It was first noted in the Pacific Northwest (PNW) occurring in the word hang by Reed (1952) and was noted by Thomas

\footnotetext{
* Authors: Drew Crosby, University of South Carolina (dmcrosby@email.sc.edu) \& Amanda Dalola, University of South Carolina (dalola@mailbox.sc.edu).

1 This is in contrast to Labov et al.'s (2006) characterization of Western vowels.
} 
(1958: 151) as occurring "without any clear regional patterns," in "[beg] for bag, [eyri] for angry, and [ejkr] for anchor." It was examined extensively by Zeller (1997), who found that younger speakers in Wisconsin were merging /æg/ and /eg/, and older females were raising /æg/ towards /eg/ but not merging them. Bauer \& Parker (2008), also examined BAG-raising in the speakers of Wisconsin, but unlike Zeller (1997) found that /æg/ neither merges with / $/$ / nor /e/. They show that /æg/ starts at the canonical position of /æ/ and rises to a position near the onset of /e/. They do support Zeller's (1997) finding that /æg/ and /eg/ merge phonologically with speakers having reanalyzed the /e/ in /eg/ as /æ/. Further supporting these findings, Benson, Fox, and Balkman (2011) find universal /æ/-raising in all 27 of their respondents from Northwest Wisconsin, with advanced /æ/-raising and fronting in 23 of their 27 respondents (85\%) and find no phonetic merger of $/ æ g /$ with either $/ \varepsilon /$ or $/ \mathrm{e} / .^{2}$

BEG-raising appears to be much less widespread than BAG-raising outside of the Pacific Northwest. Wassink (2016) notes that "only anecdotal evidence exists of raising / $/ \varepsilon /$ to $\left[\mathrm{e}^{\mathrm{I}}\right]$ in $e g g$, leg to $\left[\mathrm{e}^{\mathrm{I}} \mathrm{g}, \mathrm{l} \mathrm{e}^{\mathrm{I}} \mathrm{g}\right.$ ] occurring sporadically in other parts of the United States. It is only in the Southern Shift reports that we find documentation of more productive / $\varepsilon /$-raising (Labov, Ash, and Boberg 2006, 248). Here / $\varepsilon /$ raised and developed an in-glide to yield the stereotypically Southern [eiə] bet as [beiət]" (p. 80). It was not even noted in the PNW apart from a brief mention by Reed (1961) until the work of Wassink, Squizzero, Schirra, and Conn (2009) (Wassink 2017).

In the specific case of Pacific Northwest English (PNWE), BAG-raising and BEG-raising must be examined together. Wassink et al. (2009) finds that "that while some males overlap all

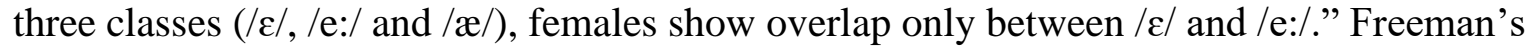
(2014) work supports this, finding that all speakers do indeed merge / $\mathrm{gg} / \mathrm{and} / \mathrm{eg} / \mathrm{at}$ a lower height than non-pre-velar /e/. She further adds that both males and females across two generations of Seattle speakers BAG-raise. ${ }^{3}$ The older male-group displayed a wide overlap between / æg/ and both /عg/ and /eg/, and the younger female group showed both the most variability in BAG-raising and the lowest height for /æg/. Riebold (2015), furthers this analysis by including a wider range of ages, ethnicity ${ }^{4}$, socio-economic status, and network strength score (NSS), which represents how closely participants are socially connected to the local community. He finds that only NSS and age are statistically significant. NSS was correlated with more prevelar raising, and BAG-raising and BEG-raising both peaked in Generation 2, with Generation 3 (age 18-36) showing more raising than Generation 1 (older than 62). ${ }^{5}$ However, in contrast, Wassink (2015) argues that BAG-raising is spreading in the younger generation. Her youngest participants (born 1976-1986) show the greatest degree of "complete spectral overlap" between /e/ and /æg/ of all three generations and the two younger generations displaying /æg/ and / $\mathrm{\varepsilon g} /{ }^{6}$ On the other hand, Stanley (2018), finds data somewhat more in line with Freeman (2014). The speakers in Cowlitz

\footnotetext{
2 They define general /æ/ as /æ/ being realized at a higher tongue position (lower F1) than /a/ and "advanced fronting and raising" to be /æ/ being realized at a tongue position higher and fronter (higher F2) tongue position than $/ \varepsilon /$ ${ }^{3}$ Generation 2 was defined to be age 37-62, and Generation 3 was defined to be age 18-36 (Freeman 2014). Although not mentioned directly, these age categories appear to be based on emically defined age categories as discussed in Wassink (2015). Generation 1 was defined to be that born before 1950. Both Freeman (2014) and Wassink (2015) are part of the Pacific Northwest English Study.

${ }^{4} \mathrm{He}$ looks at participants from five ethnicities in Washington: African-American, Caucasian, Japanese-American, and Yakima-Nation.

${ }^{5}$ Although, Riebold (2015) does not mention it appears his generations are largely comparable to Freeman's (2014) and Wassink (2015). He does, however, point out that Freeman's (2014) speakers form a subset of his data, which is also from the Pacific Northwest English Study.

${ }^{6}$ Wassink (2015) did not look at the small BAGEL-class as BAG-raising and BEG-raising were both unexpected.
} 
County in Southwestern Washington showed a decline in the use of BAG-raising among the younger generation born after 1973, which he links to a decline in the timber industry and concomitant decline in the local economy and locals' positive feelings toward the county.

Despite the phonological similarities between BAG-raising in the Midwest and BAG-raising in the PNW, Mielke et al. (2017) uses an ultra-sound study of speakers to show that the articulation of these clusters actually differs between the two regions. Midwestern speakers were found to front $/ \mathrm{g} /$ relative to $/ \mathrm{k} /$. Mielke et al. (2017) argues that this relative frontness of $/ \mathrm{g} / \mathrm{may}$ be the original basis for BAG-raising. However, a difference in the articulation of $/ \mathrm{k} / \mathrm{and} / \mathrm{g} / \mathrm{was}$ not found in speakers from the Pacific Northwest, leading Mielke et al. (2017) to conclude that BAG-raising spread as a phonological rule (without an articulatory basis) to the PNW. This contrasts with Wassink's (2017) analysis of the phenomenon who argues that since "The dialect literature shows no clear evidence of this pattern in the regions whose speakers settled the Pacific Northwest," it is "difficult to argue that this pattern was inherited" (79-80). Instead, she argues that this phenomenon is due to velar pinch, which causes F3 to lower and F2 to rise and makes the preceding vowel sound higher and fronter than its tongue position would otherwise imply.

3. Spokane. Despite BAG-raising's regional markedness within the western dialect region of the United States and phonological BEG-raising's uniqueness more-widely, these seemingly related phenomena have been little studied outside of the Seattle metropolitan area within the state of Washington, the only exceptions being Riebold (2015) and Wassink (2017) for Central/Eastern Washington and Stanley (2018) for Southwestern Washington. This is despite widely acknowledged cultural differences between Eastern and Western Washington. This divide is often referred to as The Cascade Curtain (Wiley 1992; Jenkins 2015): Western Washington is viewed as more urban and liberal and Eastern Washington as more conservative and rural. Some legislators in the state have even called for the less populous Eastern half to secede and form its own state free from the liberal policies of the more populous western half (Camden 2016a). This cultural split is also born out in Evans' (2013) perceptual dialectology study of the state. When participants were asked to draw lines on a map of Washington State around areas that they thought spoke differently and provide a label, two primary divides were noted. These were the previously mentioned East-West divide and an urban-rural divide. In the former, there was a tendency for the Eastern half of the state to be labeled as "country" and "hick" (Evans 2013: 286); in the latter, urban areas were identified with diversity, gangs, and higher education (Evans 2013: 279). One place that falls into both the Eastern-Washington and urban divides but that has not been studied much sociophonetically is the city of Spokane. The city of Spokane is the second largest in the state of Washington, after Seattle, with an estimated population of 219,190 as of July 1, 2019 ("United States Census Bureau QuickFacts" 2020), six different colleges within a thirty-mile radius ("Colleges Near Spokane" 2020), and more liberal tendencies than its surrounding region (Camden 2016b). Although, BAG-raising has been studied in the surrounding region by Riebold (2015), who found that region was not a significant predictor of the data presented in his thesis, and Wassink (2017), who found that her participants did participate in BAGraising with similar values to those of Seattle, no study has looked specifically at speakers from the city of Spokane. This lack of dialectal data (aside from one speaker in Labov et al. (2006)) for an important regional city and the lack of data on the social conditioning of BAG-raising and BEG-raising in Washington state calls for a new study.

4. Research Questions. The present study examines BAG and BEG-raising in Spokane English. It was designed to answer the following questions: 
1. What position in $\mathrm{F} 1 \mathrm{xF} 2$ space do the non-high prevelar vowels occupy relative to their canonical counterparts for speakers from Spokane, WA?

2.What social factors, (i.e. gender, age, education, ideology, experience living outside PNW) affect BAG-raising in Spokane, WA?

3. What social factors, (i.e. gender, age, education, ideology, experience living outside PNW) influence BEG-raising in Spokane, WA?

\section{Methods.}

5.1. PARTICIPANTS. The participants in this study were one 55-year-old male (hereafter EO7), one 54-year-old male (hereafter BI9) one 27-year-old male (hereafter LR8), and one 23-year-old female (hereafter SY11), all from Spokane County, Washington. All participants had some college except for EO7 who had a high school diploma. All participants identified themselves as white or Caucasian except LR8 who identified as white/Japanese(-American) and both EO7 and LR8 had lived more than one year outside of the PNW at some point during their lives, whereas neither BI9 or SY11 had lived outside of the PNW at any point.

5.2. STIMULI. This stimuli for the study consisted of four-tasks and a sociolinguistic interview. The tasks were a wordlist task, a rhyming task, a reading passage, a game of Go Fish, and a sociolinguistic interview. The wordlist consisted of forty words. Eight words were of the BAG-class, nine words of the BEG-class, and four words of the BAGEL-class (word containing /e/ before /g/ in stressed monosyllabic or disyllabic words). Along with these, there were three words each from the BAT-class, BET-class, and BAIT-class (specifically words from these classes ending in an oral non-g stop). The remaining ten words were distractors. Each word was recorded twice in the frame sentence "Say ___ again". The second task was a simple rhyming task in which participants were asked to read eleven sentences of the form "does (word) rhyme with (other word)." The participants were then instructed to read the reading passage, "The Cat and the Mice" developed by Freeman (2014) that targets BAG, BEG, and BAGEL-class words (word containing /e/ before /g/ in stressed syllables) from a sheet of paper. This was followed by a game of Go Fish. There were twelve pictures, four of each printed, cut out, and taped to standard playing cards. There were two cards to represent each of the BAG-class, BEG-class, and BAGEL-class words, one each for BAT and BET and three distractors. ${ }^{7}$ Finally, speakers participated in a sociolinguistic interview that focused on questions attempting to elicit target words (e.g., a question about hunting to elicit /bag/ and /tag/) and making the speaker less conscious of their speech (e.g., questions about their work). The equipment used for recording was a Marantz Professional Solid-State Recorder, Model PMD661 MKIII, recording at 44.1 kHz with 16-bit quantization.

5.3. PROCEDURE. The researcher started the experiment by giving a brief outline of the research and the procedures involved (e.g., I'm studying the speech of the Spokane area. Today, I'll have you read a list of forty words, answer a few questions, and have you read a short story. Then we'll play a game of Go Fish, and I'll interview you for about 45 minutes). The participants were then asked to fill out the demographic questionnaire and a consent form. The researcher then showed them how to put on the headset and began the interview. For the wordlist task, participants were presented with 40 words using a Microsoft Powerpoint slideshow with five words listed on each slide in random order in the frame, "Say again." Subjects were asked to

\footnotetext{
7 There was also supposed to be a card for the BAIT-class words as well but due to an oversight on the part of the researcher this was not included in the game.
} 
repeat each sentence twice, the second repetition of the word immediately following the first (e.g., participants said "please say bag again, please say bag again"). The rhyming task followed and was also presented on Powerpoint, with four questions for the first two slides and three for the last one. The participants were asked to read the question and then answer yes or no. Participants were then asked to read the reading passage from a sheet of paper once. This was followed by the game of Go Fish. The participants were first shown the pictures that would appear on the cards through a Powerpoint slide and asked if they knew what each of the pictures represented and if not were informed via an indirect phrase. ${ }^{8}$ The researcher then checked that the participant knew the rules and informed the participant that instead of asking the standard question: "Do you have any __ " they should ask "Do you have a ___ ? ?", and instead of the standard replies "Here" or "Go Fish," they should reply "Yes, I have a _ " or "No, I don't have a ." The researcher dealt out five cards to each player and asked the participant to begin the game. Upon conclusion of the game, the researcher began the sociolinguistic interview, each of which lasted a minimum of 45 minutes.

5.4. MEASUREMENTS. In examining research question one above measurements of the first, second, and third formants of all four speaker's BAG-class, BEG-class and BAGEL-classes vowels were taken at $25 \%, 50 \%$, and $75 \%$ of the vowel's length in order to reduce co-articulatory effects and to examine the degree of diphthongization of the vowels. ${ }^{9}$ The same procedure was applied to a selection of the speaker's BAT-class, BET-class, and BAIT-class vowels to allow for a comparison of prevelar vowels with their canonical positions. In examining research questions two and three above, the present study relies on auditory analysis similar to Labov's (1972b) department store study, but with added safeguards, notably the use of spectrograms and waveforms, as well as the ability to check each token multiple times using Praat (version 6.0.32; Boersma and Weenick, 2017). The researcher listened for instances of either [eI] or [æ] in BAGclass words and coded instances of the former with a 1 and instances of the latter with a 0 . The same basic procedure was applied to BEG-class words with instances of [er] being recorded as a 1 and instances of $[\varepsilon]$ being recorded as a 0 . In both cases, the spectrogram of the relevant token was checked for diphthongization and relative height to confirm the auditory analysis, as in Figure 1 below, where the continuously falling F1 and rising F2 suggest a rising and fronting diphthong more similar to [er] than the canonically monophthongal $[\varepsilon]$ that would be expected in other varieties of American English.

Data for analysis was pooled from the wordlist task, the reading task, the Go Fish task and the sociolinguistic interview for BAG, BEG, and BAGEL-class words. For BAT, BET, and BAIT-class words, data was pooled from the wordlist task, reading task, and the Go Fish game, along with 15 additional tokens for the BAIT-class words from the sociolinguistic interview, in order to supplement the lack of one of these cards from the Go Fish game.

In terms of statistical analyses, occurrence of BAG-raising and occurrence of BEG-raising were submitted to a stepwise logistic regression with gender, age group (20s or 50s), education, and experience living outside the PNW as a within-subjects factor. These two analyses were computed using the $\operatorname{glm}()$ and $\operatorname{lm}($ ) functions of the lmerTest package (Kuzentsova, Brockhoff and Christensen 2017) in the statistical tool R (R Core Team, 2018).

\footnotetext{
${ }^{8}$ For example, if a participant did not recognize the picture of Reagan, they were informed that he was the president before the older President Bush.

${ }^{9}$ Due to the coarticulatory effects of the following velar on the BEG, BEG, and BAGEL-class vowels, ultimately only $25 \%$ and $50 \%$ of vowel length were used for measurements.
} 

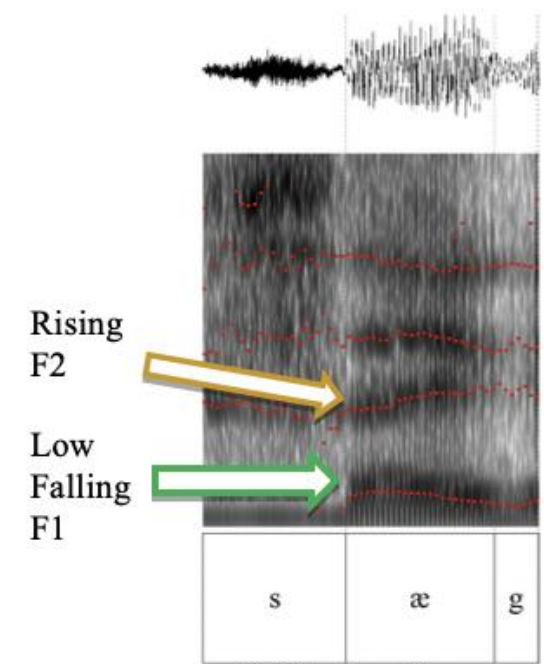

a. BAG-raised 'egg'

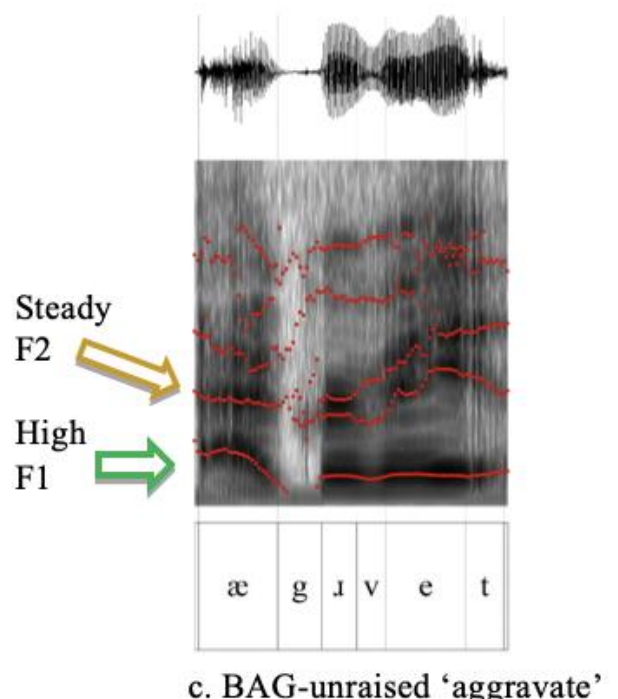

c. BAG-unraised 'aggravate'
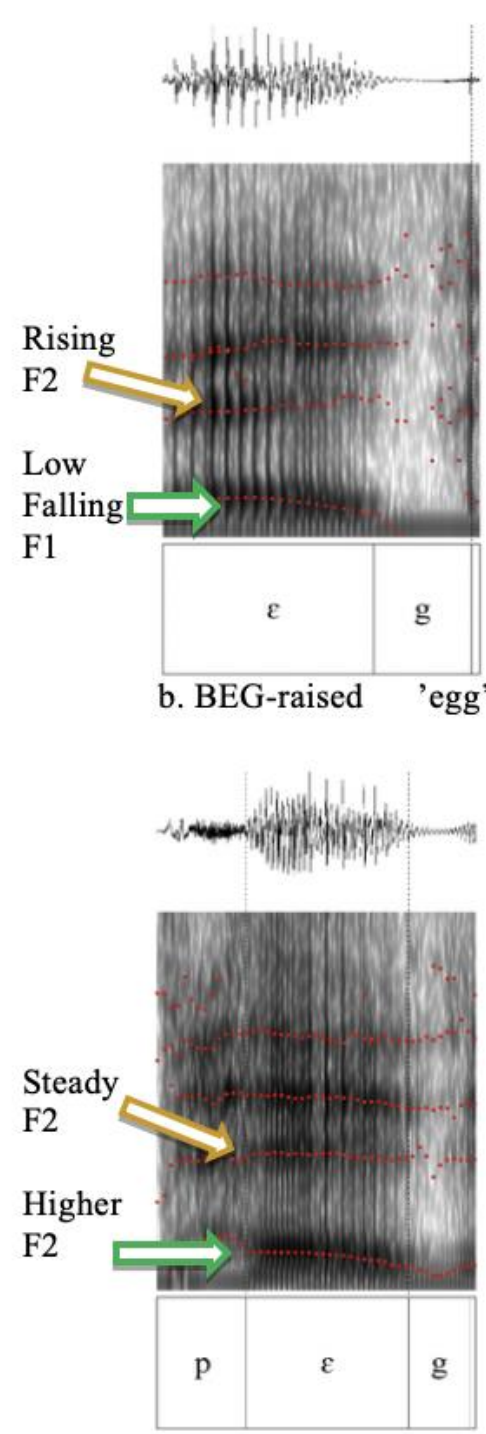

d. BEG-unraised 'peg'

Figure 1. Raised and unraised prevelar tokens All tokens from speaker SY11

\section{Results.}

6.1. Research QUeSTION 1: Vowel SpaCE. To answer Research Question 1, descriptive analyses of the data were carried out using Microsoft Excel, and vowel normalization and plotting was done using Thomas \& Kendell's (2017) Vowel Normalization and Plotting Suite, "NORM". Unfortunately, "NORM" only plots vowels using two sets of vowels measurements and not the three that were planned when data measurements were being carried out. Plotting using $75 \%$ of the vowel length resulted in the vowels across speakers all showing strong formant in the same direction. This shows that at $75 \%$ of the vowel duration, the speech formants are undergoing strong co-articulatory effects, so instead $25 \%$ and $50 \%$ of vowel duration were used as the reference points for plotting purposes. The results of the plotting are shown below in Figure 2.

For the four speakers analyzed here two clear patters emerge. For speakers BI9 and SY11, the prevelar vowels classes pattern together. There is a substantial degree of overlap between the 
prevelar vowel classes and the BET vowel class at $25 \%$ degree of vowel duration, with the prevelar vowels gliding in the same direction as the BAIT vowel. On the other hand, the prevelar classes of EO7 and LR8 pattern more closely with their non-prevelar counterparts. For both speakers we see clear separation of the BAG and BAGEL vowels with BEG overlapping with BAGEL only slightly and BEG overlapping with BAG slightly in the case of LR8 and not all for EO7. Furthermore, the BAG-class vowels also move in a similar downward direction as their non-prevelar counterpart, BAT-class vowels. However, the BEG-class vowels do have a degree and direction of movement like the BAGEL and BAIT vowels. Finally, the BAGEL vowels for BI9 and SY11 are substantially lower and backer than non-prevelar BAIT. This differs from EO7 and LR8 whose BAGEL-class vowels are largely within their BAIT-class vowels.

SY11: 23-year-old Female

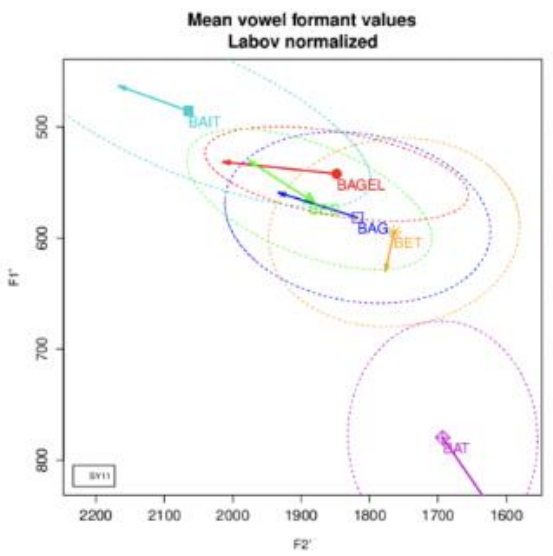

LR8: 27-year-old Male

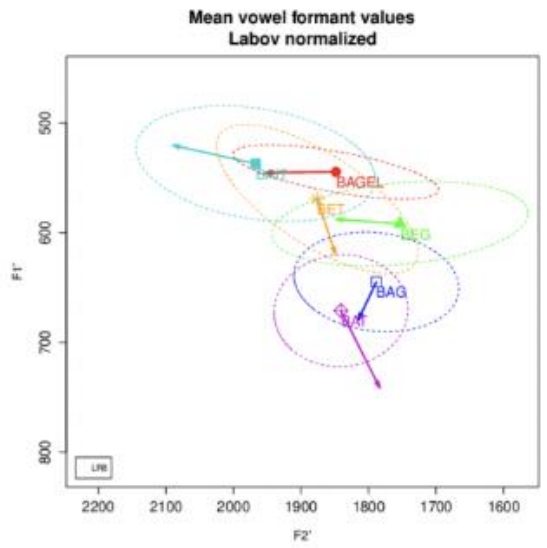

BI9: 53-year-old Male

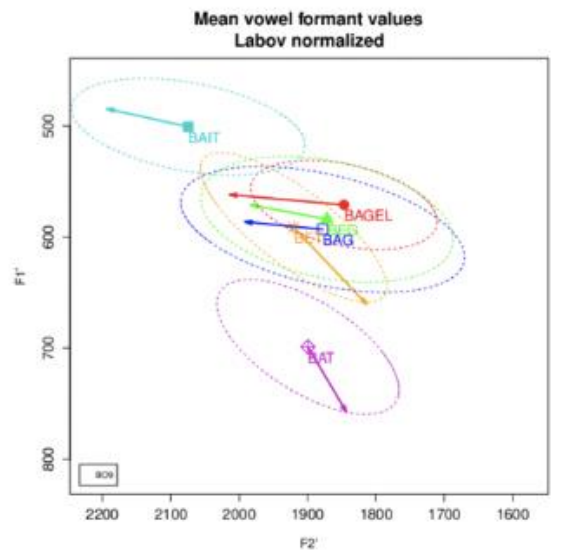

EO7: 54-year-old male

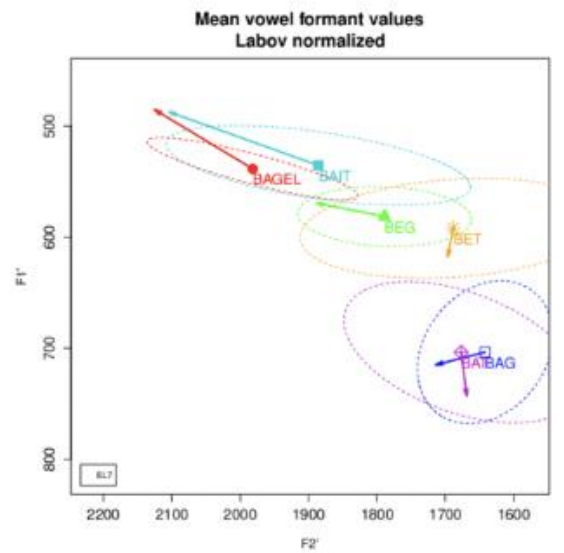

Figure 2. NORM plots of front vowel space (ovals at one standard deviation)

6.2. RESEARCH QUESTION 2: BAG-RAISING. Bar plots for presence of auditory BAG-raising for each participant is given below in Figure 3. In order to model the occurrence of BAG-raising, a stepwise logistic regression was performed performance with gender, age group (20s or 50s), education, and experience living outside the PNW as the independent variables. 


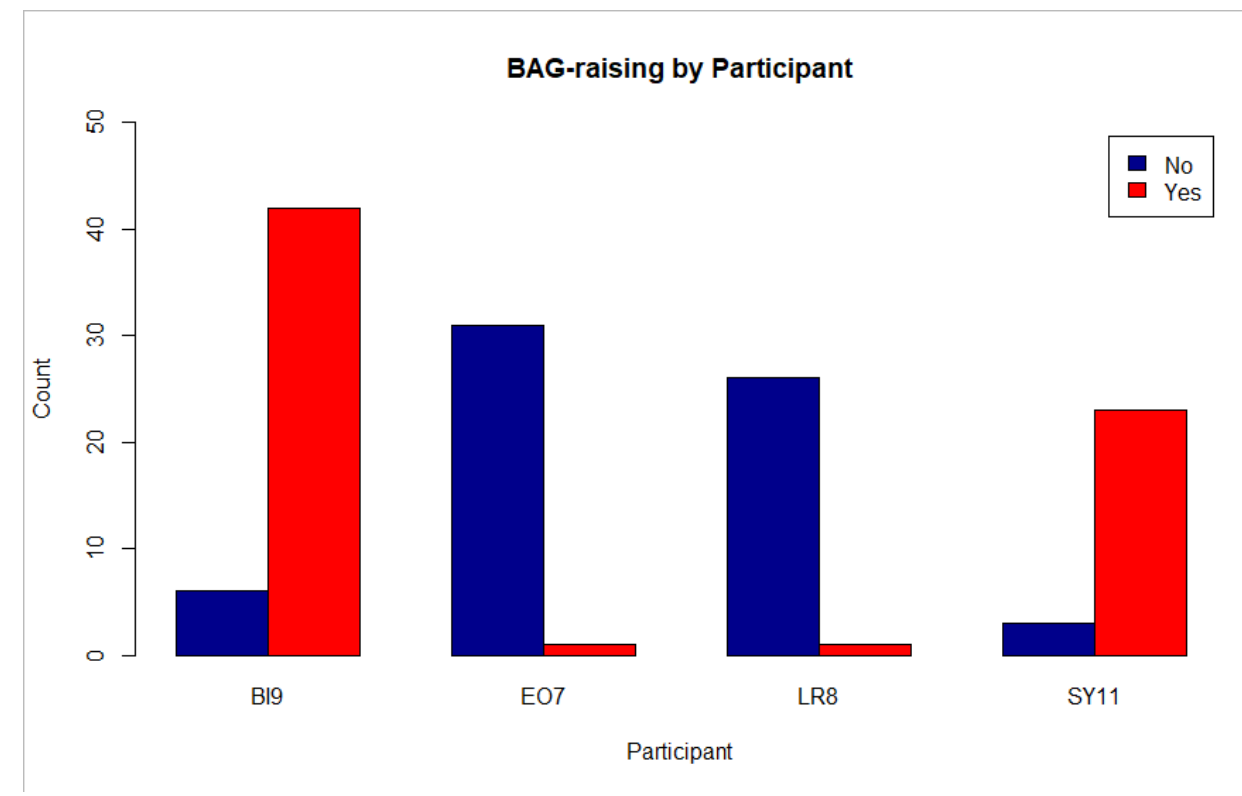

Figure 3. BAG-raising counts by participant

Results of this logistic regression found a main effect for experience living outside the PNW ( $\mathrm{p}<.001)$ such that speakers who had lived outside the PNW were $99.452 \%$ times less likely to BAG-raise than participants who had not. Counts for this are shown in Figure 4 and the logistic regression in Table 1.

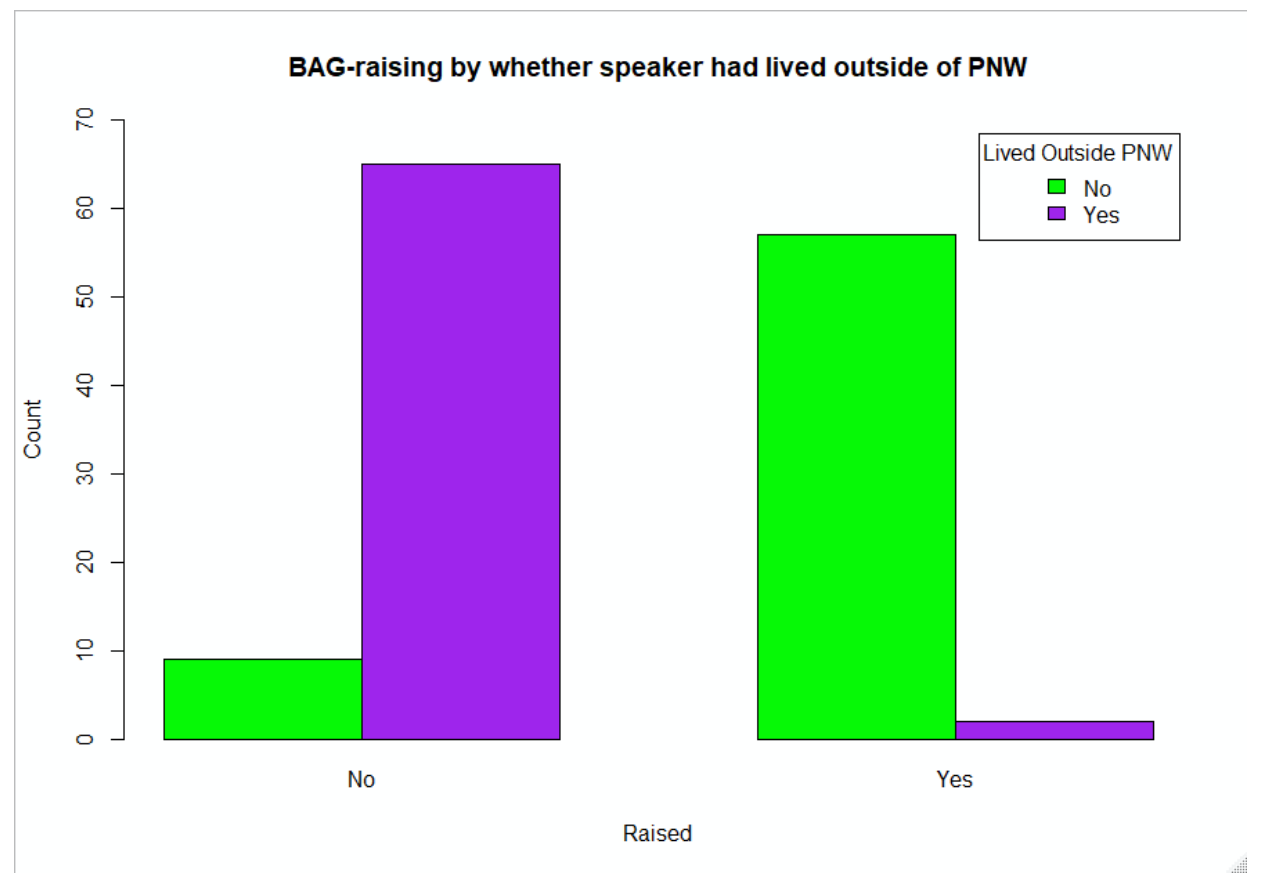

Figure 4. BAG-raising by whether speaker had lived outside the PNW 


\begin{tabular}{|c|c|c|c|c|}
\hline & Odds Ratio & Lower CI & Upper CI & p-values \\
\hline Intercept & 6.400 & 3.446 & 13.259 & $0.000 * * *$ \\
\hline Lived outside PNW & .00548 & .000813 & .0212 & $0.000 * * *$ \\
\hline \multicolumn{4}{|r|}{ Note. $* * * *=\mathrm{p}<.0001, * * *=\mathrm{p}<.001, * *=\mathrm{p}<.01, *=\mathrm{p}<.05$} \\
\hline
\end{tabular}

Table 1. Logistic regression model for BAG-raising (Experience outside PNW)

Another possible predictor that directly mirrors experience living outside the PNW emerged during the sociolinguistic interview. This category was attitude toward the variable. Just as both EO7 and LR8 had lived outside the PNW, they also expressed negative attitudes toward BAGraising. Both speakers' expression of this attitude occurred when the interviewer was explaining the goal of the study to the participants. Upon being asked whether Spokanites speak differently from people from other parts of the U.S., LR8 gave 'bag' as an example and when asked how he felt about it replied, "I think [BAG-raising] is incorrect. There is no ' $y$ ' before the ' $\mathrm{g}$ '." Similarly, when the research explaining that certain people in the PNW pronounce 'bag', 'beg', and bagel' similarly, EO8 immediately follows with another example of "incorrect" speech: "or sometimes people say this is 'are' house ' $A$ ' ' $R$ ' ' $E$ ', no it's 'our' house ' $O$ ' ' $U$ ' ' $R$ ' ... because they've never been taught properly." In contrast to this SY11, noted that people from Idaho pronounce 'bag' differently without passing any judgement on the variable and BI9 expressed ignorance of the phenomenon, also without judgement.

A new logistic regression ran with BAG-raising counts as a dependent variable and ideology, gender, age group (20s or 50s), and education as independent variables produced the same results as experience living outside the $P N W$ (which is to be expected as those two speakers with negative attitudes toward the variable are also those who had lived outside the PNW), such that those who held negative attitudes toward the variable were $99.452 \%$ less likely to BAG-raise than those who did not. These results are shown below in Figure 4 and Table 2. 


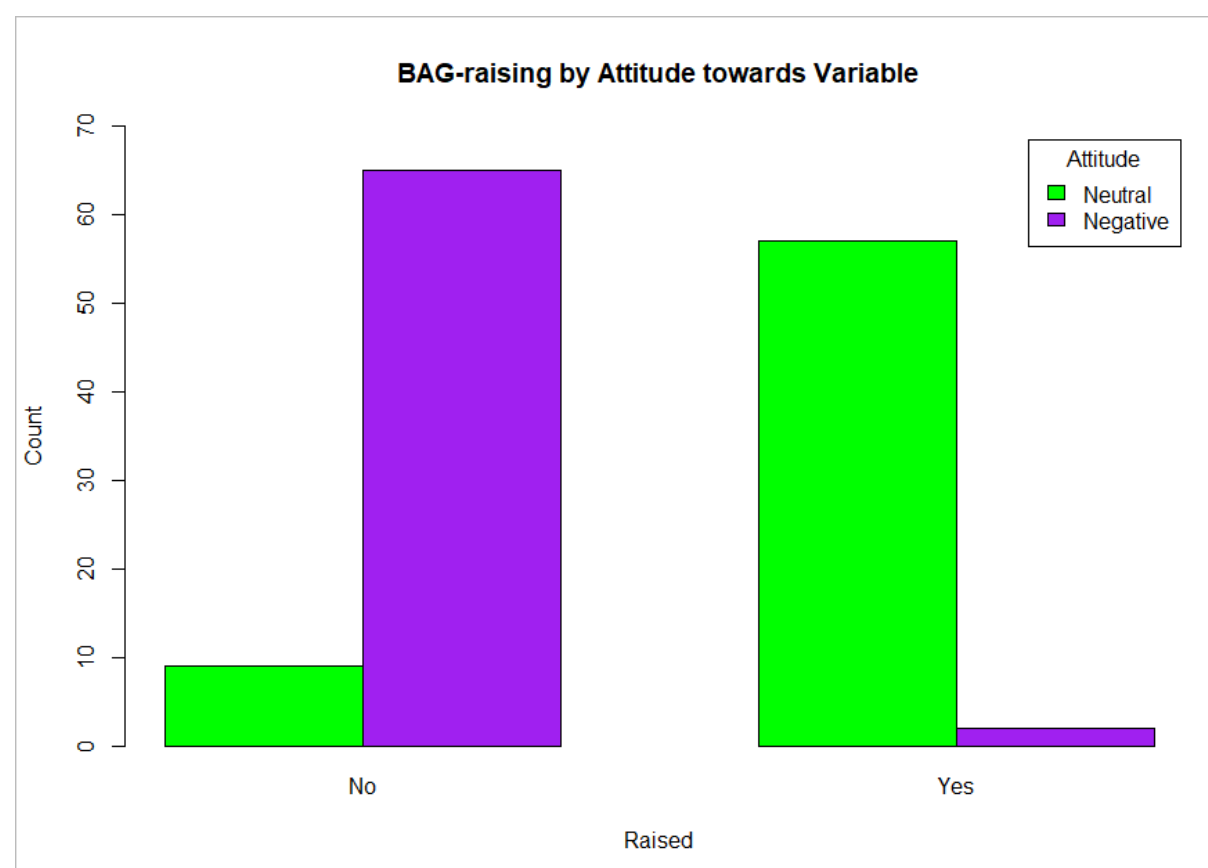

Figure 4. BAG-raising counts by attitude towards variable.

\begin{tabular}{|c|c|c|c|c|}
\hline & Odds Ratio & Lower CI & Upper CI & p-values \\
\hline Intercept & 6.400 & 3.446 & 13.259 & $0.000 * * *$ \\
\hline Negative Attitude & .00548 & .000813 & .0212 & $0.000 * * *$ \\
\hline \multicolumn{2}{|r|}{ Note. $*^{* * *}=\mathrm{p}<.0001, * * *=\mathrm{p}<.001, * *=\mathrm{p}<.01, *=\mathrm{p}<.05$} \\
\hline
\end{tabular}

Table 2. Logistic regression model by attitude toward BAG-raising (Attitude)

6.3. RESEARCH QUESTION 3. Bar plots for presence of auditory BEG-raising for each participant is given below in Figure 5. In order to model the occurrence of BEG-raising, a stepwise logistic regression was performed performance with occurrence of EG-raising as dependent variable and gender, age group (20s or 50s), education, and experience living outside the PNW as the independent variables. 


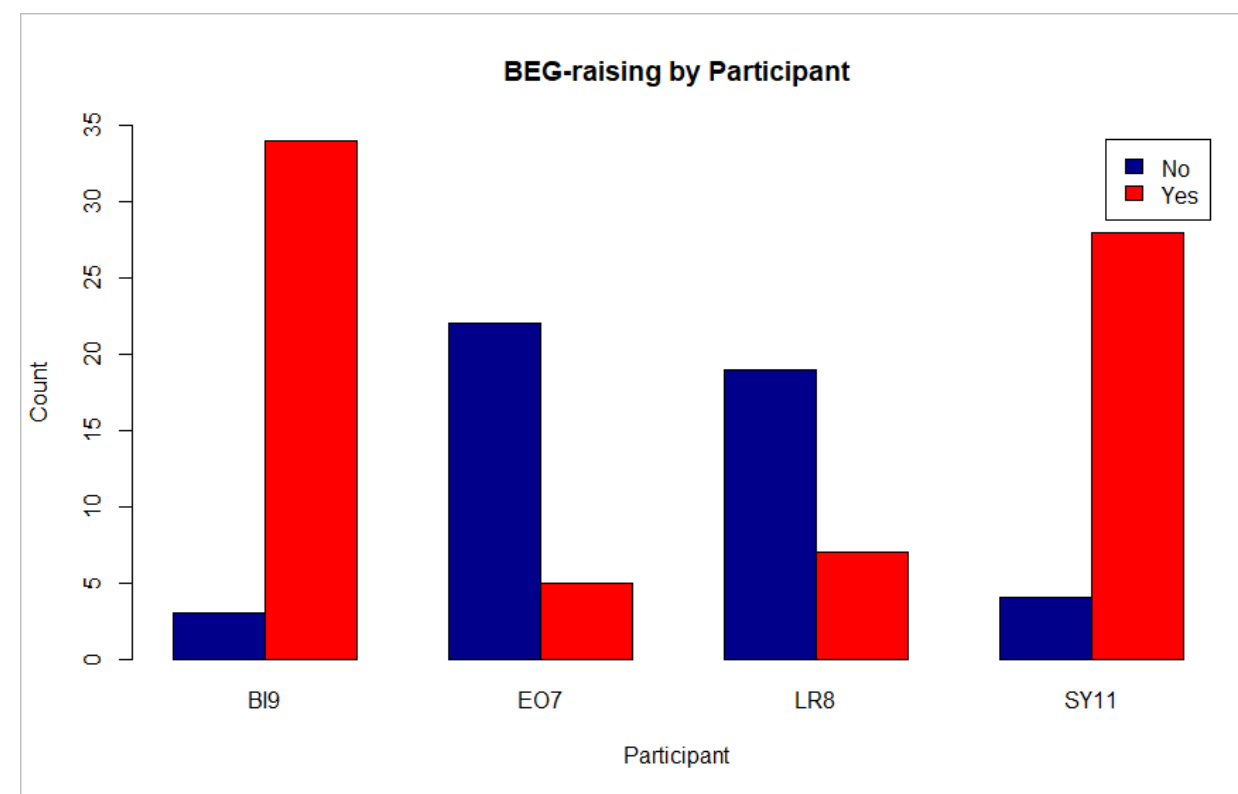

Figure 5. BEG-raising counts by participant

Results of this logistic regression found a main effect for experience living outside the PNW $(\mathrm{p}<.001)$ such that speakers who had lived outside the PNW were $96.585 \%$ times less likely to BEG-raise than participants who had not. Counts for this are shown in Figure 6 and the logistic regression in Table 3.

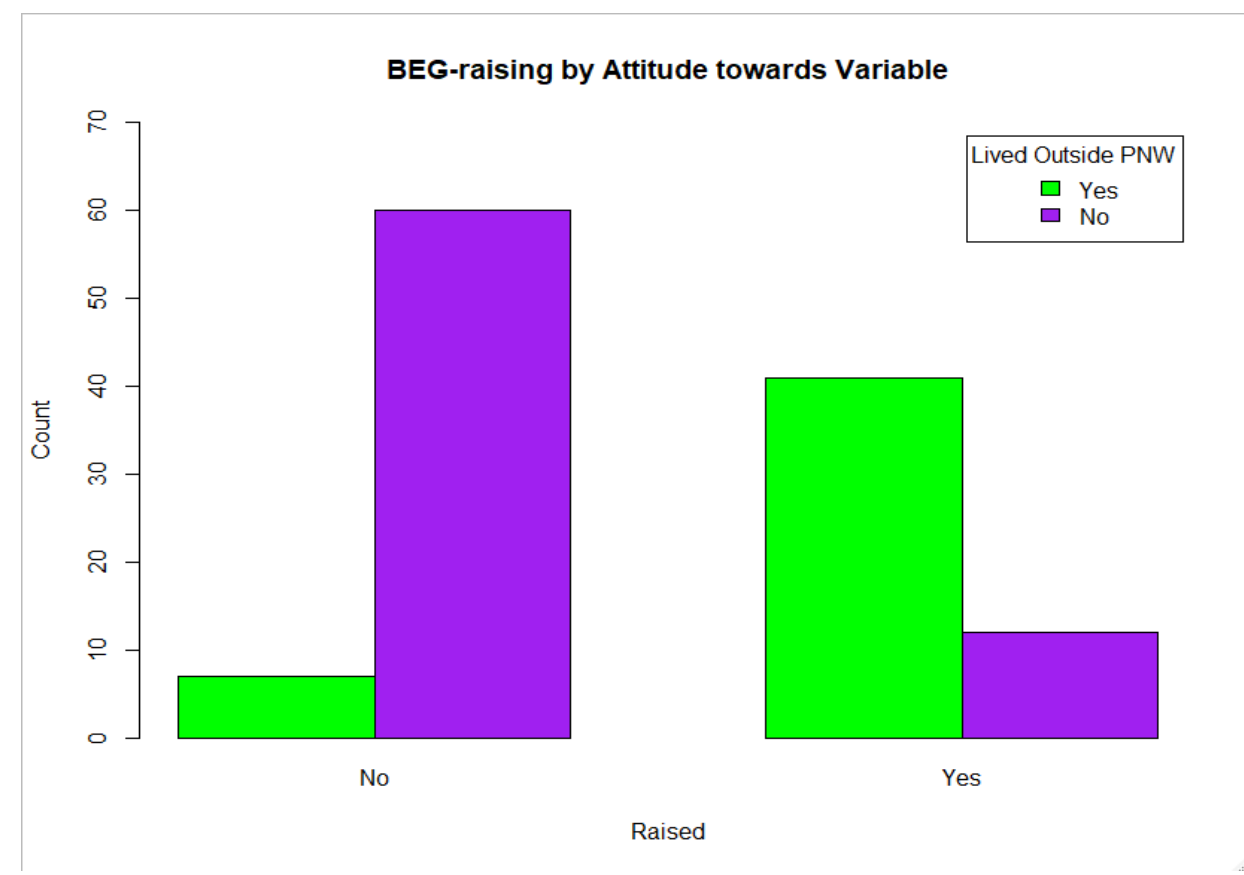

Figure 6. BEG-raising by whether speaker had lived outside the PNW 


\begin{tabular}{|c|c|c|c|c|}
\hline & Odds Ratio & Lower CI & Upper CI & p-values \\
\hline Intercept & 8.571 & 4.202 & 20.602 & $0.000 * * *$ \\
\hline Lived outside PNW & .0341 & .0115 & .0889 & $0.000 * * *$ \\
\hline \multicolumn{2}{|r|}{ Note. $* * * *=p<.0001, * * *=p<.001, * *=p<.01, *=p<.05$} \\
\hline
\end{tabular}

Table 3: Logistic regression model for BEG-raising (Experience outside PNW)

The correlation regarding BEG-raising and attitudes toward it are less clear than for BAGraising given that LR8's comment was directed specifically at BAG-raising. However, if we assume that the analysis can be extended to include any sort of prescriptive linguistic ideology affecting non-standard forms, we find that BEG-raising and ideology have the same correlations, as BEG-raising and experience living outside the PNW as was the case for BAG-raising. ${ }^{10}$

Accordingly, a new stepwise logistic regression was run with BEG-raising as a dependent variable and ideology as an independent variable, in addition to those mentioned previously. The regression selected a best fitting model with ideology as the only significant predictor, such that those holding prescriptive ideologies were $96.585 \%$ less likely to BEG-raise than those who did not. These results are shown below in Figure 7 and Table 4.

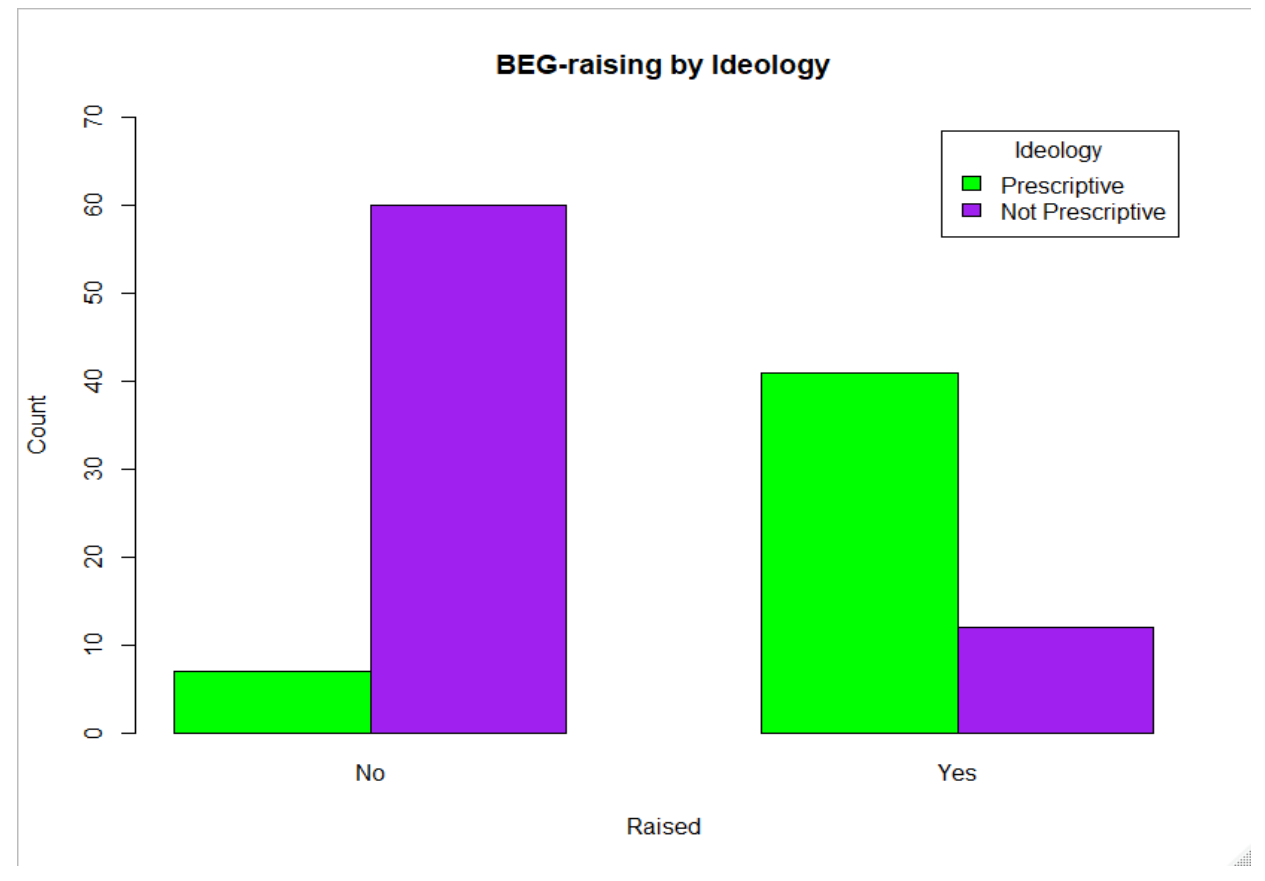

Figure 7. BAG-raising counts by ideology

\footnotetext{
${ }^{10}$ Albeit, SY11 did express a negative attitude towards the form 'Warshington', saying that it "highly annoys me... because [she] was raised to say Washington and speak "properly", with air quotes around that word". However, she did indicate through verbally air quoting 'properly' that she views this as a personal preference rather than attaching any sort of moral judgement to the form.
} 


\begin{tabular}{|c|c|c|c|c|}
\hline & Odds Ratio & Lower CI & Upper CI & p-values \\
\hline Intercept & 8.571 & 4.202 & 20.602 & $0.000 * * *$ \\
\hline Prescriptive Ideology & .0341 & .0115 & .0889 & $0.000 * * *$ \\
\hline \multicolumn{2}{|r|}{ Note. $* * * *=p<.0001, * * *=p<.001, * *=p<.01, *=p<.05$} \\
\hline
\end{tabular}

Table 4. Logistic regression model for BEG-raising (Ideology)

\section{Discussion.}

7.1. RESEARCH QUESTION 1. The data for this research question largely supports previous work. In terms of BAG-raising it finds speakers with a range of overlaps between BAG and BEG to those who have near complete overlap. This is largely in accordance with previous work on PNWE which finds a range of degrees of mergers across speakers and speaker groups. In terms of BEG-raising it suggests that not all speakers have BEG and BAGEL fully merged spectrally. This is contrary to previous work, such as Freeman (2014) which shows the BAG and BAGEL vowels spectrally merged across all speakers. This lack of complete spectral merger, along with the fact that the directionality of BEG-class words matches that of BAGEL and BAIT-class words for all speakers, suggests that at least for some speakers in Spokane BEG-raising is in the process of merging rather than fully merged spectrally.

7.2. RESEARCH QUESTION 2. The above suggest two new possible conditioning factors for BAGraising in the PNW generally and Spokane specifically. These are experience living outside the PNW and attitude towards the variable. The former case is contrary to Riebold (2015) who found no significant correlation between regionality and prevelar-raising in Washington State as a whole. This may very well be the case given the small sample size of this study. Nevertheless, the present study suggests that an investigation of BAG-raising that investigates locality in terms of percentage of life spent in the area or a more complex methodology, such as Reed's (2016) rootedness metric, which takes into account a speaker's orientation toward their place of origin and desire to remain, may be warranted. The connection of BAG-raising with ideology is, however, more interesting in that it suggests, not only that BAG-raising varies between Labovian indicator and Labovian stereotype, depending on the speaker, but also that it suggests that there is a connection between a speaker's attitude towards a variable and how often the speaker uses it in their own speech. Becker, Aden, Best, and Jacobson (2016) have also shown a connection between prevelar raising and ideology in Oregon, but they find that it correlates with an ideology on non-accent rather than inversely correlating with having a negative attitude towards prevelar raising.

7.3. RESEARCH QUESTION 3. The patterns found in this study connecting BEG-raising and experience living outside the PNW and ideology are similar to those found for BAG-raising, in that experience living outside the PNW and holding prescriptive ideologies predict a lower use of BEG-raising. However, the patterns are not quite as robust. This can be seen in the case of experience living outside the PNW, by comparing Figure 3 and Figure 6, where those who had-lived outside the PNW were more likely to BEG-raise than to BAG-raise. This is especially the case with ideology. which is defined more loosely than the negative attitude towards the variable that was used to predict BAG-raising.

8. Conclusion. The present study has suggested some further avenues of inquiry with regards to prevelar raising in Spokane, Washington. Specifically, these are that experience prevelar raising 
living outside the PNW may predict lower rates of prevelar raising and that negative attitudes held toward BAG-raising predict lower rates of its usage.

Still, the current study suffers from a number of limitations. Chief among these are the low sample size of this study and the use of an acoustically-informed auditory analysis rather than a purely formant-based acoustic analysis for the statistical portion of the study. Furthermore, the ideological component of the study came about as an unintentional result of the sociolinguistic interview and the measurement of locality was rather simplistic. Future research could naturally improve upon these issues by increasing the sample size of speakers from Spokane, including a comprehensively quantitative acoustic analysis of prevelar raising, developing to attempt to more systematically elicit attitudes towards prevelar raising and including a more complex measurement of locality. Finally, speakers from understudied areas in the region, such as North Idaho, might be also be included as well to determine the geographical spread of see what the status of Eastern Washington prevelar raising is.

\section{References}

Bauer, Matt \& Frank Parker. 2008. /ae/-Raising in Wisconsin English. American Speech 83(4). 403-431. https://doi.org/10.1215/00031283-2008-029.

Becker, Kara, Anna Aden, Katelyn Best \& Haley Jacobson. 2016. Variation In West Coast English: The case of Oregon. American Speech 91(5). 107-134. https://doi.org/10.1215/00031283-3772923.

Benson, Erica J., Michael J. Fox \& Jared Balkman. 2011. The bag that Scott bought: The low vowels in Northwest Wisconsin. American Speech 86(3). 271-311. https://doi.org/10.1215/00031283-1503910.

Boersma, Paul \& Weenink, David. 2017. Praat: Doing phonetics by computer [Computer program]. Version 6.0.32, retrieved 29 August 2017 from http://www.praat.org/.

Camden, Jim. 2016a. A deep dive into the presidential results in Spokane County. The Spokesman Review. https://www.spokesman.com/blogs/spincontrol/2016/nov/19/deep-divepresidential-results-spokane-county/.

Camden, Jim. 2016b. Matt Shea, Bob McCaslin propose creating new state called "Liberty" in Eastern Washington. The Spokesman Review. https://www.spokesman.com/stories/2016/dec/07/matt-shea-bob-mccaslin-propose-creating-new-state-/.

Colleges Near Spokane. CollegeSimply. https://www.collegesimply.com/colleges-near/washington/spokane/ (19 February 2020).

Eckert, Penelope. Vowel shifts in Northern California and the Detroit suburbs. Stanford University. https://web.stanford.edu/ eckert/vowels.html (18 February 2020).

Evans, Betsy E. 2013. Seattle to Spokane: Mapping perceptions of English in Washington State. Journal of English Linguistics 41(3). 268-291. https://doi.org/10.1177/0075424213494822.

Freeeman, Valerie. 2014. Bag, beg, bagel: Prevelar raising and merger in Pacific Northwest. University of Washington Working Papers in Linguistics 32. 1-23. https://linguistics.washington.edu/research/publications/bag-beg-bagel-prevelar-raising-andmerger-pacific-northwest-english/.

Jenkins, Don. 2015. One Washington, two sides. Capital Press. https://www.capitalpress.com/state/washington/one-washington-two-sides/article_2bb114fe-69b9-51d6-acdba8a275f7d9e2.html. 
Kuznetsova, Alexandra, Per B. Brockhoff \& Rune H.B. Christensen. 2017. 1merTest Package: Tests in Linear Mixed Effects Models. Journal of Statistical Software 82(13). 1-26. https://www.jstatsoft.org/article/view/v082i13.

Labov, William. 1972. The social stratification of (r) in New York City department stores. In William Labov (ed.), Sociolinguistic patterns. Philadelphia: University of Pennsylvania Press. 168-178.

Labov, William, Sharon Ash \& Charles Boberg. 2006. The atlas of North American English: Phonetics, phonology, and sound change: A multimedia reference tool. Berlin: Mouton de Gruyter.

Mielke, Jeff, Christopher Carignan \& Erik R. Thomas. 2017. The articulatory dynamics of prevelar and pre-nasal /æ/-raising in English: An ultrasound study. The Journal of the Acoustical Society of America 142(1). 332-349. https://doi.org/10.1121/1.4991348.

R Core Team. 2018. R: A language and environment for statistical computing. R Foundation for Statistical Computing, Vienna, Austria. URL https:/www.R-project.org/.

Reed, Carroll E. 1952. The pronunciation of English in the state of Washington. American Speech 27(3). 186. https://www.jstor.org/stable/453476.

Reed, Carroll E. 1961. The pronunciation of English in the Pacific Northwest. Language 37(4). 559-564. https://www.jstor.org/stable/411357.

Riebold, John M. 2015. The social distribution of a regional dhange: /æg, $\varepsilon g$, eg/ in Washington State. Seattle: University of Washington dissertation. http://hdl.handle.net/1773/33996.

Stanley, Joseph A. 2018. Changes in the timber industry as a catastrophic event: BAG-raising in Cowlitz County, Washington. University of Pennsylvania Working Papers 24(2). 137146. https://repository.upenn.edu/pwpl/vol24/iss2/16/.

Thomas, Charles Kenneth. 1958. An introduction to the phonetics of American English. New York: Ronald Press.

U.S. Census Bureau QuickFacts: Spokane city, Washington. United States Census Bureau. https://www.census.gov/quickfacts/fact/table/spokanecitywashington/AGE295218 (19 February, 2020).

Wassink, Alicia, Robert Squizzero, Rachel Schirra \& Jeffrey Conn. Effects of gender and style on fronting and raising of /æ/, /e:/ and /\&/ before /g/ in Seattle English (abstract). New Ways of Analyzing Variation (NWAV). 38. http://www.sociolinguistics.uottawa.ca/nwav38/abstractsWassink(2009)Effects_of_Gender.pdf.

Wassink, Alicia Beckford. 2015. Sociolinguistic patterns in Seattle English. Language Variation and Change 27(1). 31-58. https://doi.org/10.1017/S0954394514000234.

Wassink, Alicia Beckford. 2016. 5. The vowels of Washington State. American Speech 91(5). 77-105. https://doi.org/10.1215/00031283-3772912.

Wiley, John K. 1992. 'Cascade curtain' symbol of a state's split personality. Los Angeles Times. http://articles.latimes.com/1992-02-02/local/me-1796_1_washington-state.

Zeller, Christine. 1997. The investigation of a sound change in progress: /æ/ to /e/ in Midwestern American English. Journal of English Linguistics 25(2). 142-155. https://doi.org/10.1177/007542429702500207. 